\title{
SOCIAL EMOTIONAL MODEL FOR COPING WITH LEARNING AMONG ADOLESCENT SECONDARY SCHOOL STUDENTS
}

\author{
MWITA SOSPETER, THERESIA J. SHAVEGA AND COSMAS MNYANYI
}

(Received 2, October 2020; Revision Accepted 9, November 2020)

\begin{abstract}
Social emotions are frequently experienced in every individual in the daily life including adolescents' secondary school students. The mult-social emotional changes such as aggressive and happiness among adolescents influences students coping with learning at school. The purpose of this study was to develop social emotional model for coping with learning among adolescent secondary school students. Specifically the study attempted to answer the extent social emotional model is effective in improving students coping with learning. The study adapted collaborative action research design in which a total of 244 adolescent secondary school students responded to questionnaires and focus group discussion. The effectiveness of the developed social emotional model for student coping with learning was reported by students through the questionnaires. It was found that the aspects incorporated in the model improved practices in learning outcomes to both teachers and students in coping with learning. It was found that, Teachers used guidance and counseling, action oriented activities such as role play, encouraging play and exploration as the strategies to foster active engagement among adolescent secondary school students towards learning adjustment. Furthermore, the study revealed positive significant because the data in the model summary shows that the value of $r=.351$ indicates that one item for adolescent secondary school students coping with learning increased for about $35.1 \%$ with $77.5 \%$ standard error of the estimated predictor value. Although this study was conducted in Tanzania employing moderate sample size from which the data was gathered with the help of collaboration action research design. The findings provide guidelines for further replicate research on social emotion behaviours and academic performance in education elsewhere.
\end{abstract}

KEYWORDS: Social Emotional Behaviour, Adolescent, coping, learning

\section{INTRODUCTION}

Schools are the central site for the development and promotion of children social emotional wellbeing (Panayiotou, Humphrey, \& Wigelsworth, 2019) and by nature the primary development of children functioning in the society.

Mwita Sospeter, Agency for the Development of Educational Management (ADEM)

P.O.BOX 71 Bagamoyo

Theresia J. Shavega, Faculty of Education, the Open University of Tanzania P.O.BOX 23409

Dar es Salaam

Cosmas Mnyanyi, Faculty of Education, the Open University of Tanzania,
Thus, there has been alerting on adolescent students demonstrating various social emotional behaviours (Sospeter, Shavega, \& Mnyanyi, 2020), such as happiness, isolation and aggressive social emotions like fighting, anger and rudeness in schools. These social emotion behaviours in one way may have impediment of 
adolescent student success in learning and connectedness at school (Panayiotou et al., 2019, Sospeter et al., 2020). Similarly, scholars argue that students social emotional behaviours attributes to positive or negative learning habits at school (Hymel, 2014; Swearer \& Hymel, 2015). Students may develop low learning habits as a results of failure in identifying oneself, stress management, social awareness and aggressive management the vice versa is true.

It is estimated that $28 \%$ of adolescents aged $13-$ 19 years, experience social emotional challenges such as depression, anxiety and isolation, 13-15 years with the rate of $3 \%-7 \%$ and under 13 years fewer than 1\%-2\% (Karevold, 2008). This implies that adolescents between the ages of 13 to 19 years are at a risk of being affected by the social emotion problems (Sospeter et al., 2020). Furthermore, adolescent secondary school students demonstrate social emotional problems ranging from $16 \%$ to $41 \%$ (Pathak, et al., 2017; Pathak et al., 2011). In India it is estimated that social emotional problems among students ranged from $14 \%$ to $50 \%$ (Pathak et al., 2011b), which may impede students coping in learning. Hymel (2014) maintain that social emotional challenges among students are one of the strongest reasons for students' failure in academic achievement hence dropout from schooling. The poorly developed social emotions results to school refusal, poor school performance and difficulty in maintaining relationship with other students and poor engagement in learning task at school (Maclntyre \& Vincze, 2017; Musoga, 2017).

It is argued that social emotions challenges may hamper learner social emotional competencies which are critical for self-regulation, emotion management and logical thinking during decision making (McCormick et al., 2015). This means social emotion control the child attention, influence his or her motivation to learn, modify the choice of learning strategies and affect his or her self-regulation of learning (Maclntyre \& Vincze, 2017). This is the case in Tanzania (Shavega, Brugman, \& van Tuijl, 2014) found that the teachers-child relationship at school controlled the children emotions regulation and enhanced pro-social emotions among children at school. Generally, emotion are part of students' identity and thus affect personality development, psychological health and physical health (Lahey, 2003; Maclntyre \& Meza, 2016) which are important in determining academic success. Likewise, Rowe and Fitness (2015) maintain that social emotional problems affect students' logical, analytical and critical thinking during learning process. Also, they are detrimental to motivation, active engagement and in-prioritisation in information processing among students during learning process (Ekman, 2016).

However, social emotion are potential in motivating students to attain their goals, because reinforces and reduce error making among students through seeking help from others (Vogl \& Pekrun, 2016). Rowe and Fitness (2018) added that, developing Social Emotional Learning (SEL) model among adolescent secondary school students enable them cope with learning. Universally Social and Emotional Learning (SEL) programmes promote communication skills, decision making and relationship skills among adolescents (Nuryana, Ayu, \& Dewi, 2016, Panayiotou et al., 2019). Thus, through the implementation of SEL programmes in schools can improve adolescent social emotional skills. Studies indicate that SEL programme are worthy for children coping with interpersonal and intrapersonal difficulties during schooling (Bates, 2012, Weissberg, 2011). Maclntyre and Vincze (2017) added that they enhance new ideas beyond given rules of assimilation and reduces level of students' withdrawal from the learning task at school. Universal SEL programmes include curricula designed to promote social emotional skills among children (McComirk et al., 2015). Cristovao et al., (2017) viewed SEL models as the ability to recognise, manage emotions, solve problems effectively and establish relationship with others. SEL skills include social awareness, self-awareness, self-management, responsive in decision making and relationship skills (Goleman, 2011; McComirk et al., 2015). These skills are appealing to be helpful among adolescent because they help in coping with learning by improving their emotional skills and mindset (Esnari, 2017; Weissberg, 2011). It is anticipated that SEL programmes are implemented to students through training them to cope with learning, as a result of improved social emotional skills (Cristovao et al., 2017).

However, no empirical evidence in Tanzania on the designed and tested SEL model which is implemented in secondary schools helping adolescent secondary school students cope with learning difficulty. Thus, it is imperative to develop and test the effectiveness of social emotional model for adolescent students coping with learning at school. Doing so may provide 
evidence why SEL programmes are appearing helpful to students' coping with learning at school (Weissberg, 2015).

\section{Purpose of the Study}

The current study tested the designed social emotional model for coping with learning among adolescent secondary school students in public schools. Specifically the study attempted to answer the extent social emotional model improve students coping with at schools.

\section{Theoretical Perspective of the Study}

This study was governed by functionalism theory. The theory was proposed by many scholars including Talcott Parsons, Robert Merton and Emile Durkheim (Yakkaldevi, 2014). Functionalism or structural functionalism was developed by August Comte around 1800s who was called the father of sociology (Turner, 2014). To Comte the essence of functionalism is to see the particular social structures and their effects as the social organisms in the environment. Spencer further added that individual is to function if four needs are met (Turner, 2014). These needs include operation, reproduction, regulation and distribution. Durkheim (1895) extended the theory from Herbert Spencer. Functionalists argue that the society should be understood as a system of interdependent parts (Sato, 2011). The theoretical perspective taken toward social emotional development in childhood is a combination of functionalist theory and dynamical system (Saarni, 2011).

This study adapted functionalism theory as it views emotions as bidirectional processes of establishing, maintaining, and/or disrupting significant relationships between an organism and the (external or internal) environment (Barrett \& Campos, 1987).This is to say for adolescent secondary school students to learn better their social emotional needs should be addressed to bring them in the acceptable mood of learning at school. Moreover, the students are thought to function like organisms with various social emotional developments working together like organ to maintain and develop habits of learning at school.

\section{Strategies and Materials Designed to Improve SESs among Adolescent Students}

Studies suggest that schools should meet the social and emotional developmental needs of students for effective teaching and learning (Brackett, Rivers, Reyes \& Salovey, 2012). For students to learn effectively in school, safety and conducive environment are essential as it increases students' social emotional competencies. Rivers and Brackett (2013) added that Social Emotional Learning (SEL) programming results in significant shifts in social, emotional and academic competencies as well as improvement in the quality of learning environment among students. In the same way, structuring routines and fun activities improve students' social emotional skills as they enjoy engaging in structured and fun activities at school (Corso, 2007).

The study by Ensari (2017) in California USA used micro-expression training intending to improve emotional skills among adolescent students. The study employed quasiexperimental design whereby pre-post-test was carried out in a class involving high school students. Before, the pre-test was carried out to students; students were given shortened microexpression pre-test and asked to complete them. The intention was to familiarize them with the test conduction. The findings indicated that, students in the treatment (training) group show improvement in comparison to control group (non-training). This implies that students' emotional skills were improved as they were less stressed.

Moreover, the study by Durlak et al., (2011) in Chicago on high school students pointed out that, applying SEL programmes to students help in reducing behaviours such bullying drug abuse and use, interpersonal violence at school. Their persistence at school helps them to cope with learning. SEL include Social awareness, selfmanagement, responsive decisions making, selfawareness, recognition and self-regulation and relationship skills (Bates, 2012; Goleman, 2011). In addition, the quality of SEL programmes at school provides students with opportunities to contribute in class, school and experience satisfaction which enhance their motivation of learning at school (Davey et al, 2008). In the same way, Gross (2014) depicted a five level emotion regulation model (see figure 1). In the model he established that coping is not similar to emotion regulation. Emotion regulation encompasses the goals to be accomplished, the strategy to be used to accomplish it and the consequences (outcomes) in trying to achieve the particular emotion regulation goal. It is obvious that when individual struggle to regulate their emotion the primary focus is on decreasing negative emotion such as sadness, anger, anxiety and intensify positive emotion. But indeed emotion regulation is more than this. This is 


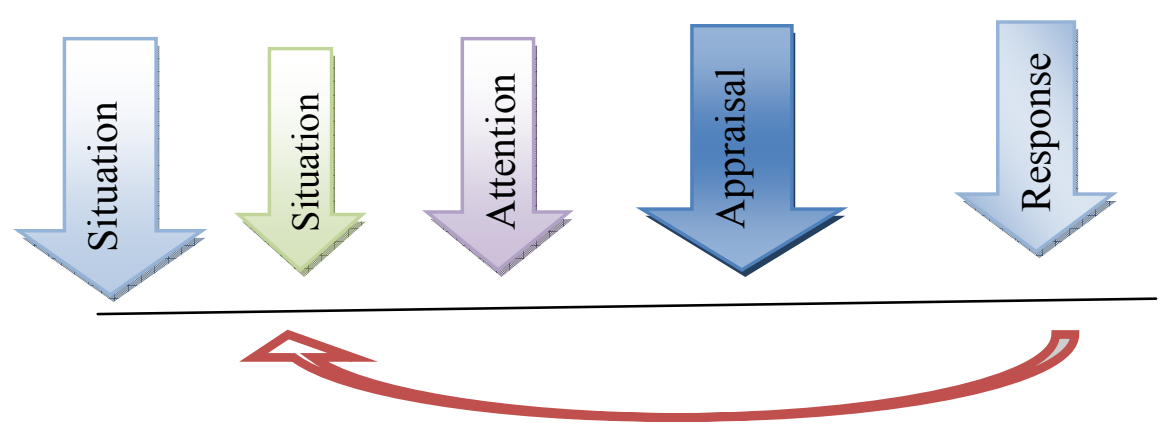

Source: Gross (2014), Figure 1: Emotion regulation model

The study by Mbae (2013) in Kenya shows that collaborative classroom approach was the strategy used to maximise the students' social emotional skills which in turn influence their academic achievement. The study established numbers of strategies used to improve social emotional skills; these were peer tutoring, cooperative learning and consulting experts. As discussed by (Jones, Zaslow, Darling-churchill, \& Halle, 2016) adolescent social emotional skills lay the foundation of children later success in life and academic achievement during schooling. It is established that children who better resolve conflicts with peers, self-regulate emotions and cooperate with peers at school significantly adjust in learning hence are connected with peers and develop learning interest at school (Jones et al., 2016; Jones \& Bouffard, 2012; Sospeter et al., 2020).

Despite of numerous studies conducted worldwide on social emotional among adolescent secondary school students and the strategies behind improving these social emotional skills among them (Cristovao et al., 2017; Ensari, 2017; Mbae, 2017). Unlike, there was no known intervention study in Tanzania addressing these social emotional challenges among adolescent secondary school students. This study was imperative as it hypothesizes that playing, attachment, guidance and counselling, expressing feeling to friends as well as action oriented activities significantly predicts students connectedness, raise interest to learn and improve classroom engagement among adolescent at school.

\section{RESEARCH METHODOLOGY Research Paradigm}

The paradigm is the worldviews that give direction in the approaches and the design to be used in conducting the research (Crewel, 2013). Thus, pragmatic governed this study. Pragmatic is derived from the word of pierce, James Dewey (Cresswel, 2014). Pragmatic views the world based on action, situation and consequences. Adolescent secondary school students have faced number of challenges including failure in coping with learning, fight and bullying other at school. The situation calls for pragmatic solution as way of helping these adolescent smoothly cope with learning at school.

Also, the paradigm was adapted because it was useful for model development based on the account that social emotion regulation encompasses goals, strategy and consequences achieved when trying to achieve the goal of emotion regulation to cope with the acceptable situation. Pragmatic is concern with works and solutions to problems (Licoln, 2011). Tashakkori and Teddlie (2010) assert that the philosophy is suitable because it accept mixing approaches towards providing solutions to problems at hand. Thus, quasi-experiment and collaboration research design were integrated toward developing social emotional model for students coping with learning at school. CAR used as the main approach to bring about change among adolescent secondary school students (Mnyanyi, 2014). The researcher collaboratively involved teachers as the way to link theory and practices aiming at refining, testing and evaluating strategies for improving adolescent secondary school students' connectedness and learning interest. It is argued that involving participants 
(teachers and students) as the co-researchers improve teaching and learning environment as they participate in the action research cycle (Mnyanyi, 2014).

The study was carried out within two public secondary schools in Hai District. The choice of these two public secondary schools in Hai District was due to the reasons that the schools had experiencing serious cases of students with social emotion problems such as aggressive and isolation with peers which may have resulted into failure in coping with learning (Jones, et al., 2017). Moreover, no evidence on such similar studies conducted in this area particularly in secondary schools.

The sample size was calculated based on the formula developed by Yamane (1973) who argue that a precision of $10 \%$ is reasonable for qualitative study. In the same vein, Sospeter (2017) maintains that, for mixed approach the best sample size is $10-20 \%$ of the total population under scrutiny. Therefore, based on this stance the actual sample size was obtained using the precision of $15 \%$ of the target population. This study involved a total sample size of 244 students and 10 teachers as informants. The moderate sample size used as the study employed mixed approach based on quasi-experimental design and collaboration action research (Creswell, 2013).

Purposive sampling deemed appropriate because it enabled the researchers to work with respondents with relevant information on social emotional behaviours about adolescent students (Kisanga, 2017; Kumar, 2011). Purposive sampling was used to select all discipline masters/mistress and teachers who provide guidance and counselling in the school. Since, they are responsible for teaching as well as guiding and counselling students on how they should behave for sustainable academic learning (Bryman, 2016). Stratified random sampling was used in selecting students. It is argued that the aim of stratified random sample is to reduce the potential for human bias in the selection of cases to be included in the sample. The strata included students aged $13,14,15,16$ and 17 years old. This ensured high representation of students' age in the treatment group and none treatment group as it allowed the researcher to make statistical inferences (Smith, 2013).

\section{Variables and Measurements}

Social emotional skills were studied as the independent variable and students coping with learning as the dependent variable. This study adapted Emotional Regulation Checklist (ERC) (Shield et al., 2001) to measure adolescent learning interest at school. ERC had similar constructs to Adult-reporting. The sub-constructs of the purposed study include; interest in learning, active in learning, enable students asking help from friends, attachment and academic achievement. Students learning interest and connectedness was assessed through 5-point scale (1=very low, 2=low, $3=$ Moderate, $4=$ High and $5=$ very high) which used to respond to items with higher scores indicating greater learning interest and connectedness among adolescent students in schools. The study on social emotional skills is new in Tanzania. Thus, it was urgent to view how the available measures adequately fit the Tanzania culture. Therefore, functionalism theory was useful as it helped in determining how adolescent secondary school students function like organism with various social emotional skills working together like organ to maintain and develop habits of learning at school.

\section{RESULTS}

\section{Respondents' Distribution by Gender}

The researcher targeted public secondary schools from which a sample of teachers and students as the key respondents were obtained. The respondents were asked to fill in their sex as it meant to establish if social emotional problems is gender based. It was revealed that about 138 $(56.6 \%)$ girls and $106(43.4 \%)$ boys were involved in the study. The implication is that girls seem to be many as compared to boys in secondary schools. Also, the data shows that the majority of students aged 17 years old, followed by 16 years who were $75(30.7 \%)$ and those aged 15,14 and 13years were 49, 16 and $1(0.4 \%)$ respectively. The data implies that most of adolescent in secondary school are between the age of 16 and 17 years old. Thus the sample was appropriate for data collection because this age is the mid of adolescent.

\section{Social emotional Model}

The concept of social emotional model development began to rise as the majority of the participants claimed for establishment of clear social emotions regulation model to cut across adolescent. The study shows that adolescent secondary school students are in the risk of dropping from schooling due to failure in coping with emotional problems at school. Thus, the figure below incorporates the potential components integrated in the social emotional 
model based on the participants' responses and the literature review. Thus, the findings showed that the themes in figure 2 contain the major aspects used in designing social emotional model with the integration of functionalism aspects such as cohesion, integrity, equilibrium and solidarity.

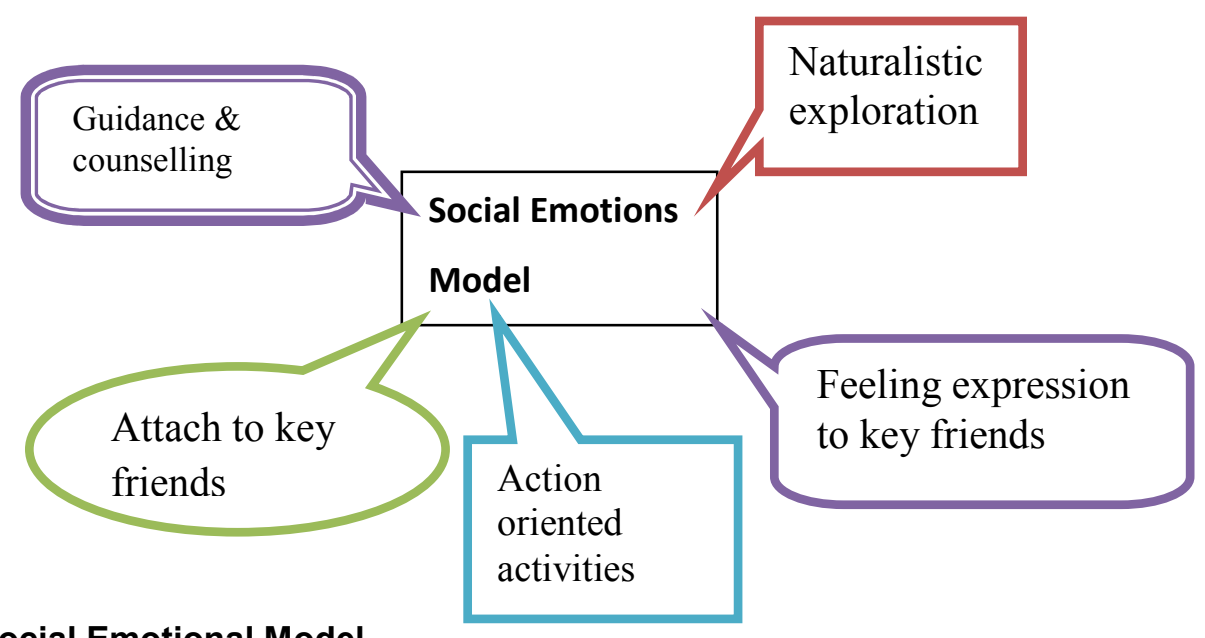

Figure 2: Social Emotional Model

Effectiveness of the proposed model in helping adolescent coping in learning

In this phase the researcher assessed the effectiveness of the model developed by collecting data about the improved practices and learning outcome among adolescent students. The aspects incorporated in the model improved practices in learning outcomes to both teachers and students in coping with difficult learning. It was reported that students had selected their key friends and were observed hugging around with them all the time at school. Teachers reported that students who previously were reluctant in learning due to being rude or aggressive have changed and they were reported improved learning outcome in the class by doing the exercise assigned.

Furthermore, the data show that high cooperation was observed among teachers and students during guidance and counselling session where students had the chance to express their emotions to teachers. The Table 1 summarise the changes observed during the implementation of model. 


\begin{tabular}{|c|c|c|}
\hline Coping strategies & 4 & How they improved the coping strategy \\
\hline Self-awareness & + & $\begin{array}{l}\text { Teacher guided students to cool down when depressed or } \\
\text { anger and control themselves when so excited. }\end{array}$ \\
\hline Choosing key friends & 4 & $\begin{array}{l}\text { Teachers encouraged students to assess themselves and } \\
\text { choose key friends who share characters. }\end{array}$ \\
\hline \multirow[t]{3}{*}{ Communicating feeling } & 4 & $\begin{array}{l}\text { Teachers guided students to choose key people whom they } \\
\text { may communicate their social emotions problems. }\end{array}$ \\
\hline & 4 & $\begin{array}{l}\text { Teachers guided student to express their taught when they } \\
\text { wish to do so. }\end{array}$ \\
\hline & 4 & Students found guiding each other. \\
\hline Self-management & 4 & $\begin{array}{l}\text { Teacher encouraged students to learn to be calm and avoid } \\
\text { provoking unnecessary. }\end{array}$ \\
\hline \multirow[t]{2}{*}{ Solidarity } & 4 & $\begin{array}{l}\text { Teachers guided students to cooperate in extracurricular } \\
\text { activities such sports and games. }\end{array}$ \\
\hline & 4 & Encouraged play and exploration \\
\hline Cohesion & $\begin{array}{l}4 \\
4 \\
4\end{array}$ & $\begin{array}{l}\text { Teachers encouraged students to learn together in groups. } \\
\text { Encourage study tour. } \\
\text { Field trip }\end{array}$ \\
\hline \multirow[t]{2}{*}{ Integration } & 4 & $\begin{array}{l}\text { Teachers encouraged play and exploration in the natural } \\
\text { context. }\end{array}$ \\
\hline & 4 & Students supported each other during learning process. \\
\hline
\end{tabular}

The findings revealed similar situation in the focus group discussion. The model was so helpful to adolescent secondary school students coping with learning as result of knowledge and social emotions skills gained during the implementation of the model. Because, some students during the discussion argued as indicated in the quotation below,

"actually our study group have been formed as a result of this model implementation... so we kindly beg our teachers to continue advising us more so that we can do better in school whenever they seen us going wrong let them not be tied of guiding us... we sometime behave the way we do behave unknowingly".

The quotation above implies that alive designed social emotional model is worthy for improved academic learning among adolescent secondary school students in public schools. Perhaps after the implementation of the model, schools seem with very minimal cases of fight, isolated and separated among adolescent. This was attained after immediate acting upon the social emotions demonstrated by adolescent at school. Furthermore, when the descriptive data run on the effectiveness of the model in helping adolescent secondary school students cope with learning. The results revealed the same situation to qualitative data; it was found that the model was effective for students coping with difficulty learning environment at school. The responses of the mean for measures for social emotional strategies ranged from 3.68 to 4.25 with most of the items hovering around the average mean of 3.92 .

The measures received the highest mean were "active participation" the designed model significantly predicted students' active participation in the classroom. "The programme activated my learning interest" and "The programme increased my attention and engagement in the class learning" represented with the mean of $4.25,4.11$ and 4.09 respectively. This implies that the model seem so effective in inducing adolescent learning interest, because it activated adolescent level of engagement in and outside the classes. Again the data show some social emotional model variables tested hovering around the average mean, these include, "interest in learning at school" and "communicating to friends when in problems" presented with the mean of $3.87,3.83$ with the standard deviation of 1.278 and 1.162 respectively (see table 2 ) The data infer that 
adolescent level of interaction, social awareness and self-awareness was raised during the implementation of the programme as they had opportunity to share different social emotional skills under the teacher guide.

Table 2: summary of the items surveyed showing effectiveness of the model for students coping in learning $(\mathrm{N}=244)$

\begin{tabular}{llll}
\hline Social emotional model Items & Mean & $\begin{array}{l}\text { Std. } \\
\text { Deviation }\end{array}$ & Variance \\
\hline Attaching to key students & 3.79 & 1.432 & 2.051 \\
Guiding and Counselling & 3.96 & 1.191 & 1.418 \\
Attaching to key friends & 3.79 & 1.281 & 1.642 \\
Raising interest in learning & 3.87 & 1.278 & 1.634 \\
Active participation in the classroom & 4.25 & 1.092 & 1.192 \\
Cope with learning at school & 3.95 & 1.078 & 1.163 \\
Social awareness among adolescent students & 3.76 & 1.218 & 1.485 \\
Assistance from other students during class sessions & 3.68 & 1.163 & 1.353 \\
Communicating feelings to friends & 3.83 & 1.162 & 1.350 \\
Attachment and engagement & 3.97 & 1.094 & 1.197 \\
Learning interest activated & 4.11 & 1.056 & 1.114 \\
Attention and engagement in class learning. & 4.09 & 1.042 & 1.086 \\
\hline Average mean & 3.92 & & \\
\hline
\end{tabular}

However, the lowest measures were the one came close falling outside the average mean. These included "social awareness, "Interest in attaching to key students" and "assistance from other students during class sessions" as shown with $(M=3.76, \quad S D=1.218, M=3.79, \quad S D=1.432$, $M=3.68$ and $S D=1.163$ ) respectively (table 2). The data show that the model was so assistive to adolescent secondary school students coping with learning. Because, it arouses students' attention and active engagement during learning process as result of social emotional problems free. It was through this model students increased courage of informing friends on their social emotions problems. This was usually done during hugging around with key friends, where they exchanged ideas on social and academic related matters.

As observed in table 2; the data for the composite variables surveyed were disaggregating with varies in means of 3.68 to 4.25 from one measure to another with the noticeable difference mean of 0.57 . The marginal differences from the highest to the lowest mean implies that the model items hover around the average mean, which means the model was so useful and effective for adolescent coping with difficulty learning situation at school. The multiple regressions were calculated for more inferring on the effectiveness of the model as summarised in table 
Table 3: Model Summary of variables used in the social emotional model development

Model Summary(b)

Change Statistics

\begin{tabular}{lllllllllll}
\hline Model & $\mathrm{R}$ & $\begin{array}{l}\mathrm{R} \mathrm{S} \\
\text { vbquare }\end{array}$ & $\begin{array}{l}\text { Adjusted } \\
\mathrm{R} \text { Square }\end{array}$ & $\begin{array}{l}\text { Std. } \\
\text { Error of } \\
\text { the } \\
\text { Estimate }\end{array}$ & $\begin{array}{l}\text { R } \\
\text { Square } \\
\text { Change }\end{array}$ & $\begin{array}{l}\mathrm{F} \\
\text { Change }\end{array}$ & df1 & df2 & $\begin{array}{l}\text { Sig. F } \\
\text { Change }\end{array}$ & $\begin{array}{l}\text { Durbin- } \\
\text { Watson }\end{array}$ \\
\hline 1 & $.351 \mathrm{a}$ & 0.123 & 0.11 & 0.775 & 0.123 & 6.683 & 5 & 238 & 0 & 1.89 \\
\hline 2 & .064 & .004 & .000 & 1.094 & .004 & 1.004 & 1 & 242 & .317 & 1.94
\end{tabular}

a. Predictors: (Constant), Natural context, guidance and counselling , Action oriented activities, Playing and exploration, Communicating feeling

b. Dependent Variable: Coping with learning at school

Source: Field Data (2019)

The data in the model summary showed that the value of $r=.351$ indicates that one item for adolescent secondary school students coping with learning increased for about $35.1 \%$ with $77.5 \%$ standard error of the estimated predictor value. Also, the measures were significant $p=.000$ and the Durbin Watson was 1.89. Andy (2009) argued that, the model summary is significant if the $R^{2}$ is less than 0.5 and the Durbin Watson is closer to 2 (see table 3 ).

Furthermore, the were positive significant correlation between guidance and counselling $(\beta=.298, t(4,239)=4.93, p=.000)$ and student coping with learning. The model summary reveal $r=351(35.1 \%)$ implying that "Natural context exploration, guidance and counselling, Action oriented activities, Playing and exploration and Communicating feeling to friends significantly predicted students learning interest among adolescent secondary school students. Likewise positive significant correlation was revealed between communication, play and exploration $(\beta=.064, t(1,242)=1.002, p=.317)$ and student connectedness. The model fit summary values indicates that $r=.064$ implying that exploring natural context and communicating feeling to key friends positively predicted students connectedness for about $64 \%$.

\section{DISCUSSION OF THE FINDINGS}

Participants praised for calling more guidance and counselling sessions among adolescent at school. The findings correspond with other scholars who depicted that adolescent stage is the period that youth developed self-identity and often try to re-establish with respect to bodily changes taking place among them (Ferreira,
Simoes, Matos, Ramiro, \& Diniz, 2012, Karimi, 2015). The study established that guidance and counselling enhance students' self-adjustment in learning activities and emotions regulation. However, students disengagement in counselling sessions established at school may be the reason for escalated poor social emotional behaviours among adolescent hence results to failure in coping with difficulty learning situation (Musoga, 2017). But, the modeling desirable emotions and behaviours among individual begins at home and continue in the facet of life (Riddin, 2018), what is learnt at home obvious build the future on which the subsequent emotions is developed among individual. School attachment is defined as the affective closeness that an actor has to a person, role or setting such that the probability of perseverance and continuance of relationship to that person is enhanced. This give rise to the famous saying "birds of the same feather flocks together". School attachment to key friends is viewed from functionalism perspective of cohesiveness, social identity, equilibrium and integrity to adolescent secondary school students which are developed as they functions like organism during schooling (Sato, 2018).

However, a study by Williams (1987) maintained that, high risk students who dropped from school lacked social network among fellow students, while those with peer affiliation and attachment reported with high academic success at school and after schooling. Finally, a longitudinal study by Ahmad et al., (2019) and Sanson, Berthelsen, and Wake (2011) matches with this study findings by identifying that student who were at grave in school learning were those with poor 
attachment to teachers, counselors, principals and fellow students. This study attempt to integrate key friends' identification and attachment at school as it seem to be the key element in stimulating social skills development among peers at school. Therefore, full adapting this idea across public secondary school implies fostering adolescent academic learning success.

Effectiveness of the designed social emotional model in enhancing learning at school

The findings reveal that social emotional model was positively associated with adolescent secondary school students coping with learning. However, some facets of SEM tested were negatively associated with students coping with difficulty learning situation. Andy (2009) argued that, the model summary is significant if the $R^{2}$ is less than 0.5 and the Durbin Watson is closer to 2. This means the model significantly correlate with students coping with learning at school. The value were consistent with similar studies focused on training adolescent with social emotional problems with anger management and impulse control programme (Fedewa, 2015). The study revealed the effect size of -.27 with the SE of 0.04 indicating smaller moderate intervention effects of the anger management and impulse training programme over anger regulation (Fedewa, 2015). The magnitude effect intervention is similar to Panayiotou et al., (2019) which published studies with the effect values $r=.031, p \leq .001$, which was consistently validated (Wang et al., 2019), with the effect size of -.25 , $p=.001$. However, little discrepancies have been witnessed on the effect size on the treatment of the facets used in the studies across world. The reasons may be due to the involvement of vary respondents, age of the respondents, economic status and regional blocs as well as the involvement of vary variables in the study. Additionally, it is theorized that the change of mind, students cohesion and well-adjusted is built through emotional security, safety and strong relationship between teachers, parents and students (Panayiotou et al., 2019). In the extent literature, guidance and counselling, play and exploration, action oriented activities create school connectedness, bonding and belonging (Durlak et al., 2011, Glennie, 2017). However, scholars lack conformed on the conceptualisation of measures of students' school connectedness (Panayiotou et al., 2019), thus from social emotional perspective this study developed a model which thought useful for adolescent coping with learning at school. In doing so, it drives children sense of self-esteem, belongingness and connectedness which are fundamental weapons for coping with difficulty learning at school (Korpershoek, Canrinus, \& Boer, 2019).

\section{CONCLUSION}

The motivation of this study arose as the personal conflicting concern the applicability of social emotional skills in rescuing adolescent grave risk from social emotional problems. In fostering successful learning the study highlighted social emotional behaviours and the strategies necessary for social emotional regulations among adolescents. Taken into account social emotional problems can both promote and obstruct learning among adolescents. The collaborative action research was imperative in designing and testing social emotional model for adolescent secondary school students coping with learning. Furthermore, the study showed that change in attitude is possible, through action research teachers collaboratively share experiences, social emotional management skills that promoted students coping with learning at school. Therefore, teachers and other education stakeholders can influence adolescent coping in learning by ensuring action oriented activities, enhancing communicating feeling, guidance and counselling as well as play and exploration during teaching and learning. These social emotional skills enhance strong bonding among adolescent 
which automatically stimulate students active engagement and interest in learning. Thus, school and decision makers in education are to foster social emotional management as a necessary tool for helping adolescent regulate their emotional problems which thought impeding their successful in coping with learning at schools. From these study findings and implication hereby recommend replicate research on social emotion behaviours and academic performance across developing countries.

\section{REFERENCES}

Ahmad, S., Peterson, E. R., Waldie, K. E., and Morton, S. M. B., 2019. Development of an Index of Socio-Emotional Competence for Preschool Children in the Growing Up in New Zealand Study. Frontiers in Education, 4(2), 1-18. https://doi.org/10.3389/feduc.2019.00002

Bento, G., and Dias, G., 2017. The importance of outdoor play for young children's healthy development. Porto Biomedical Journal, 2(5), 157-160. https://doi.org/10.1016/j.pbj.2017.03.0.

Campbell, S. B., Denham, S. A., Howarth, G. Z., Jones, S. M., Vick, J., Williford, A. P., ... Darling-churchill, K., 2016. Commentary on the review of measures of early childhood social and emotional development: Conceptualization critique, and recommendations. Journal of Applied Developmental Psychology, 45(2016), 19-41. https://doi.org/10.1016/j.appdev.2016.01. 008.

Castro, R. M. De, Isabel, D., and Pereira, F., 2019. Education and Attachment: Guidelines to Prevent School Failure. Multimodal Technologies and Interaction, 3(10), 2-17. https://doi.org/10.3390/mti3010010.

Damon, W., Lerner, R. M., and Eisenberg, N., 2006. Handbook of Child Psychology (Sixth Edit). Hoboken, New Jersey.: John Wiley and Sons, Inc.
Darling-churchill, K. E., and Lippman, L., 2016. Early childhood sociale and emotional development: Advancing the $\mathrm{fi}$ eld of measurement. Journal of Applied Developmental Psychology, 45(2016), 17.

https://doi.org/10.1016/i.appdev.2016.02. 002 .

Dunlosky, J., Rawson, K. A., Marsh, E. J., Nathan, M. J., and Willingham, D. T., 2013. Improving Students ' Learning With Effective Learning Techniques: Promising Directions From Cognitive and Educational Psychology. Psychological Science in the Public Interest, 14,(1), 458.

https://doi.org/10.1177/15291006124532 66.

Durlak, J. A., Weissberg, R. P., Dymnicki, A. B., Taylor, R. D., and Schellinger, K. B., 2011. The Impact of Enhancing Students' Social and Emotional Learning: A MetaAnalysis of School-Based Universal Interventions. Child Development, 82(1), 405-432. https://doi.org/10.1111/j.14678624.2010.01564.x

Edwards, P., 2013. An action research project examining anger and aggression with rural adolescent males participating in the Rock and Water Program. Southern Cross University.

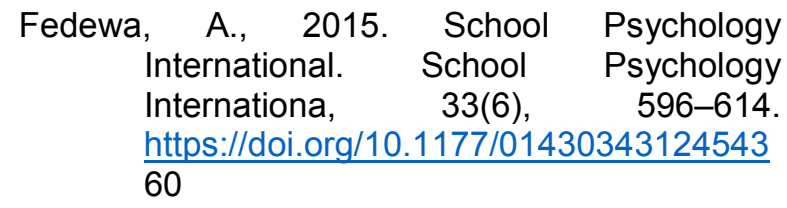

Ferreira, M., Simoes, C., Matos, M. G., Ramiro, L., and Diniz, J. A., 2012. The role of social and emotional competence on risk behaviors in adolescence. The International Journal of Emotional Education, 4(1), 43-55. Retrieved from https://login.proxy.library.emory.edu/login ?url=http://search.ebscohost.com/login.a spx?direct=true \&db=psyh\&AN=201217980-003\&site=ehostlive\%5Cnmafaldaferreira@fmh.utl.pt 
Field, A., 2009. Discovering Statistics Using SPSS (3rd editio). London: SAGE Publications Ltd.

Glaser-Zikuda, M., Stuchlikova, I., and Janik, T. (2013). Emotional Aspects of Learning and Teaching:

Reviewing the Field - Discussing the Issues. Orbis Scholae, 7(2), 7-22. https://doi.org/10.14712/23363177.2015. 18

Glennie, E. J. |Rosen. J. A. |Snyder. R.-M. M. K., 2017. Student Social and Emotional Development and Accountability: Perspective of Teachers. National Network of State Teachers of the Year, (April). Retrieved from https://eric.ed.gov/.

Granot, D., 2014. Teacher-Student Attachment and Student School Adaptation: A Variable Centered and Person Centered Analytical Approaches. American Journal of Educational Research, 2(11), 10051014. https://doi.org/10.12691/education2-11-2

Hawkins, J., Mouton, S. G., Hawkins, J., and Mcpherson, R. H., 2018. School Attachment: Perspectives of LowAttached High School Students. Educational Psychology, 16(3), 297-303. https://doi.org/10.1080/01443419601603 06

Johnson, Hillaary, and Wiener, R., 2017. This Time, With Feeling. Washington DC.

Jones, S. M., Zaslow, M., Darling-churchill, K. E., and Halle, T. G., 2016. Journal of Applied

Developmental Psychology Assessing early childhood social and emotional development: Key conceptual and measurement issues. Journal of Applied Developmental Psychology, 45, 42-48. https://doi.org/10.1016/j.appdev.2016.02. 008

Karimi, E. W., 2015. Challenges Experienced by Young- Mother Learners upon Re-entry to Formal Primary School. A case in one of the Divisions of Coastal Region, Kenya. University of Oslo.
Keltner, D., Sauter, D., Tracy, J., and Cowen, A., 2019. Emotional Expression: Advances in Basic Emotion Theory. Journal of Nonverbal Behaviours, (February), 1-48. https://doi.org/10.1007/s10919-01900293-3

Korpershoek, H., Canrinus, E. T., and Boer, $\mathrm{H}$. De., 2019. Research Papers in Education The relationships between school belonging and students motivational , social-emotional , behavioural, and academic outcomes in secondary education: a meta-analytic review. Research Papers in

Education, $\quad 00(00), \quad 1-40$. https://doi.org/10.1080/02671522.2019.1 615116

Maclntyre, P. D., and Vincze, L., 2017. Positive and negative emotions underlie motivation for L2 learning. Studies in Second Language Learning and Teaching, $\quad 7(1)$, 61. https://doi.org/10.14746/ssllt.2017.7.1.4

Markham-petro, K., 2019. Growing Citizens : Students ' Social Emotional Learning via School Gardens. Western University.

Mnyanyi, F. F., 2015. Changing Teachers ' Practices in Regular Schools Enrolling Children with Visual Impairment: An action research project in Tanzania. Åbo Akademi University Press.

Musoga, V. W., 2017. Guidance and Counseling Strategies Used by Pre-School Teachers in Managing Children's Social-Emotional Behavioural Problems in Nakuru Municipality, Kenya. Retrieved from http://ir-

library.ku.ac.ke/handle/123456789/17942

Nuryana, I., Ayu, W., and Dewi, K., 2016. Emotional Awareness and School Connectedness: A Prelimenary Study Among Students in Indonesia. Procedia Social and Behavioral Sciences, 217, 622-625.

https://doi.org/10.1016/j.sbspro.2016.02. 072 
Panayiotou, M., Humphrey, N., and Wigelsworth, M., 2019. An empirical basis for linking social and emotional learning to academic. Contemporary Educational Psychology, 56(January), 193-204. https://doi.org/10.1016/i.cedpsych.2019.0 1.009

Pang, D., Frydenberg, E., Liang, R., Deans, J., and Su, L., 2018. Improving Coping Skills and Promoting Social and Emotional Competence in Pre-Schoolers: A Pilot Study on COPE-R Program. Journal of Early Childhood Education Research, 7(2), 362-391.

Pathak, R., Sharma, R. C., Parvan, U. C., Gupta, B. P., Ojha, R. K., and Goel, N. K., 2011b. Behavioural and emotional problems in school going adolescents. Australasian Medical Journal, 4(1), 1521. https://doi.org/10.4066/AMJ.2011.464

Price, A. C., 2016. Action Research in Outdoor Learning: Promoting Social and Emotional Learning in Young People with
Social Emotional and Behavioural Difficulties. University of Birmingham.

Riddin, A. J., 2018. Dealing with increasing aggression in pre- adolescent boys as a result of pedagogical factors: A Biblical approach for Christian teachers and counsellors. At the South African Theological Seminary.

Sato, T., 2018. Functionalism: Its axiomatics. Sociopedia, 1-12. https://doi.org/10.1177/205684601332

Sospeter, M., Shavega, T., and Mnyanyi, C., 2020. Developing Social Emotional Model for Adolescent Students Coping with Learning Difficulty in Tanzania Public Secondary Schools. International Journal of Research and Innovation in Social Science, IV(II), 197-206.

Turner, J. H., 2014. Theoretical Sociology A Concise Introduction to Twelve Sociological Theories. Los Angeles: SAGE

Ltd. 